\title{
Atividade alelopática de extratos aquosos de plantas medicinais na germinação de Lactuca sativa L. e Bidens pilosa L.
}

\author{
ALVES, L.L. ${ }^{1}$; OLIVEIRA, P.V.A. ${ }^{1}$; FRANÇA, S.C. ${ }^{1}$; ALVES, P.L.C. ${ }^{2}$; PEREIRA, P.S. ${ }^{1 \star}$ \\ ${ }^{1}$ Unidade de Biotecnologia, Universidade de Ribeirão Preto, CEP: 14096-900, Ribeirão Preto-Brasil \\ *ppereira@unaerp.br ${ }^{2}$ Faculdade de Ciências Agrárias e Veterinárias, Universidade Estadual Paulista, CEP: \\ 14884-900, Jaboticabal-Brasil
}

\begin{abstract}
RESUMO: O potencial alelopático de quatro diferentes extratos de plantas medicinais (Eclipta alba, Gomphrena globosa, Tabernaemontana catharinensise Tithonia diversifolia) foi avaliado na germinação de Bidens pilosa e Lactuca sativa. Dentre os resultados obtidos no teste de germinação, notou-se um maior poder inibitório do extrato de G. globosa sobre sementes e plântulas de Bidens pilosa e Lactuca sativa independente da concentração utilizada e aumento da atividade inibitória de extratos $T$. catharinensis e de $T$. diversifolia com aumento da concentração destes. Quanto ao Índice de Velocidade de Germinação, os dados demonstraram redução do índice devido a elevada mortalidade das plântulas submetidas aos extratos de G. globosa e de $T$. catharinensis e a germinação tardia das sementes submetidas ao extrato de $T$. diversifolia. Quanto ao vigor das sementes, as menores porcentagens de sobrevivência ocorreram extratos à $2,5 \%$ para $B$. pilosa e $10 \%$ para $L$. sativa.
\end{abstract}

Palavras-chave: alelopatia, Eclipta alba, Gomphrena globosa, Tabernaemontana catharinensis, Tithonia diversifolia

\begin{abstract}
Allelopathic activity of aqueous extracts of medicinal plants on the germination of Lactuca sativa L. and Bidens pilosa $\mathrm{L}$. The allelopathic potential of four different extracts of medicinal plants (Eclipta alba, Gomphrena globosa, Tabernaemontana catharinensis and Tithonia diversifolia) was evaluated on the germination of Bidens pilosa and Lactuca sativa. The results obtained in the germination test indicated a greater inhibitory activity of G. globosa extract on Bidens pilosa and Lactuca sativa seeds and seedlings, regardlessof the used concentration, and an increase in the inhibitory activity of $T$. catharinensis and $T$. diversifolia extracts with an increase in their concentrations. As to Germination Speed Index, the data demonstrated a reduction due to the high mortality of seedlings subjected to G. globosa and $T$. catharinensis extracts and a late germination of seeds subjected to T. diversifolia extracts. As to the vigor of seeds, the smallest survival percentages occur at $2.5 \%$ for B. pilosa and at $10 \%$ for L.sativa.
\end{abstract}

Key words: allelopathy, Eclipta alba, Gomphrena globosa, Tabernaemontana catharinensis, Tithonia diversifolia

\section{INTRODUÇÃO}

Os aleloquímicos são substâncias importantes em várias linhas de pesquisas. Dentre os agentes alelopáticos, existem mais de 300 compostos secundários de plantas e microrganismos que representam várias classes químicas (Rice, 1984; Duke et al., 2000) e este número continua aumentando com pesquisas recentes mostrando interações destas substâncias com plantas e outros organismos (Macías et al., 2007). Esta diversidade de estruturas químicas dificulta os estudos de alelopatia. Outra complicação é que a origem de aleloquímico freqüentemente é obscura e a atividade biológica pode ser reduzida ou elevada pela ação microbiológica, oxidação e outras transformações. Possíveis fontes de aleloquímicos no ambiente das plantas incluem inúmeros microrganismos, certas

Recebido para publicação em 08/12/2009

Aceito para publicação em 25/02/2011

Rev. Bras. PI. Med., Botucatu, v.13, n.3, p.328-336, 2011. 
invasoras, a cultura anterior ou mesmo a atual (Bais et al., 2066). Similarmente, as espécies afetadas podem ser os microrganismos, as invasoras ou a cultura (Einhellig, 1996).

Vários tipos de compostos orgânicos foram identificados como aleloquímicos, produzidos por microrganismos ou plantas superiores (Rice, 1984; Inderjit \& Duke, 2003; Macías et al., 2007). Podem ser relacionados como principais os ácidos orgânicos solúveis em água, álcoois de cadeia reta, aldeídos alifáticos e cetonas; insaturadas simples; ácidos graxos de cadeia longa e poliacetilenos; naftoquinonas, antraquinonas e quinonas complexas; fenóis simples, ácido benzóico e derivados; ácido cinâmico e derivados; cumarinas; flavonoídes; taninos condensados e hidrolisáveis; terpenoídes e esteroídes, aminoácidos e polipeptídeos; alcalóides e cianoidrinas; sulfetos e glicosídeos; purinas e nucleosídeos.

Dentre a grande diversidade de plantas medicinais no país quatro foram utilizadas para avaliação do potencial alelopático. Dentre elas a Eclipta alba, Tithonia diversifolia, Gomphrena globosa e Tabernaemontana catharinensis.

Eclipta alba (L.) Hassk (sin. Eclipta prostrata), pertencente à família Asteraceae, é uma espécie herbácea conhecida popularmente como erva-botão. Esta espécie ocorre no Brasil e em outras regiões tropicais e subtropicais, apresenta flores brancas e metabólitos secundários como flavonóides, fitoesterois e cumestanos (Pereira et al., 1998). Eclipta alba é espécie muito conhecida pela atividade antihepatotóxica, que está correlacionada com a presença de cumestanos, como por exemplo wedelolactona e dimetilwedelolactona, e por isso recomendados para tratamento de hepatite e cirrose (Wagner et al., 1986).

O gênero Tithonia da tribo Heliantheae compreende 13 espécies, das quais sete foram investigadas quimicamente sendo isoladas lactonas sesquiterpênicas, com esqueleto carbocíclico do tipo heliangolídeo e germacrolídeo e, ainda, diterpenos e flavonóides (Baruah et al., 1979; Pérez et al., 1992; Pereira et al., 1997; Kuo \& Chen, 1998). Margaridão, Tithonia diversifolia (Hemsl.) A. Gray, é comum em certas regiões do México, América central (Schuster et al., 1992) e no Brasil é amplamente distribuído. Micromoléculas importantes, como flavonóides e terpenóides (diterpenos e lactonas sesquiterpênicas), são encontradas em gêneros da família Asteraceae (Herout, 1971).

Tanto Eclipta alba quanto Tithonia diversifolia pertencentes a família Asteraceae e a tribo Heliantheae e como característica essencial tem-se a presença de terpenóides (lactonas sesquiterpênicas) e flavonóides, substâncias com atividade alelopática em outras culturas (Almeida, 1988). Além disso, estas espécies pertencem a mesma tribo do girassol
(Helianthus annuus), o qual apresenta elevada atividade alelopática contra plantas invasoras dependendo do cultivar e da concentração do extrato (Leather, 1983; Kumar \& Gautam, 2008).

Considerando-se o número de espécies da tribo Gomphreneae e a grande diversidade dos constituintes químicos (entre os quais podemos destacar a ocorrência de betalaínas, ecdisteróides, triterpenóides, esteróides, saponinas, flavonóides e alcalóides), pode-se concluir que os gêneros ainda se encontram pouco estudados (Patterson et al., 1970; Banerji et al., 1971; Kuroda et al., 2006; Kugler et al., 2007). Com o passar do tempo, as informações sobre a fitoquímica desses vegetais podem ser adicionadas às informações botânicas anteriores levando a classificação mais precisa. Vale ressaltar que nas classes de produtos naturais acima citados são encontradas várias substâncias bioativas.

O gênero Tabernaemontana pertence a família Apocynaceae (tribo: Tabernaemontaneae). As espécies identificadas no Brasil pertencem às seções Peschiera e Bonafousia. Tabernaemontana catharinensis conhecida como leiteiro de vaca é a única espécie conhecida na Argentina e Paraguai ocorrendo também no Brasil e Bolívia (Leeuwemberg, 1994). O gênero Tabernaemontana é conhecido pelo acúmulo de alcalóides indólicos, como outras espécies incluídas na mesma subfamília (Plumerioideae). A outra sub-família, Apocynoideae, é caracterizada por acumular glicosídeos esteroidais como principais micromoléculas (Van Beek et al., 1984; Pratchayasakul et al., 2008). Além dos alcalóides estão presentes vários triterpenos e esteroídes, como lupeol, a e b-amirina, acetato de baurenila, sitosterol, etc. (Nielsen et al., 1994; Achenbach et al., 1994).

O objetivo deste estudo foi de avaliar o potencial alelopático, através do teste de germinação em placas de Petri e do ensaio in vivo em Casa de Vegetação de quatro diferentes extratos de plantas medicinais (Eclipta alba, Tithonia diversifolia, Gomphrena globosa e Tabernaemontana catharinensis), numa espécie invasora (Bidens pilosa) e uma espécie hortícola (Lactuca sativa), além de determinar a concentração ideal para esse efeito.

\section{MATERIAL E MÉTODO}

Preparo dos extratos aquosos: As amostras foliares de E. alba, T. diversifolia, G. globosa e T. catharinensis foram coletadas ao acaso das plantas da Unidade de Biotecnologia, sendo selecionadas as melhores folhas nas duas primeiras e as melhores ramificações da parte aéreas para as demais. O material vegetal in natura das espécies selecionadas foi submetido ao processo de secagem

Rev. Bras. Pl. Med., Botucatu, v.13, n.3, p.328-336, 2011. 
em estufa de circulação e renovação forçada de ar à $50^{\circ} \mathrm{C}$ por 48 horas para as partes aéreas e 24 horas para folhas. Depois de seco o material foi moído em moinho tipo Willey de faca e pesado. Após pesagem, as amostras foram transferidas para erlenmeyer de 1 litro no qual se adicionou água fervente à $100^{\circ} \mathrm{C}$ obedecendo a proporção de 3 a 3,5:1 em relação ao volume de água $(\mathrm{mL})$ por peso do substrato $(\mathrm{g})$. Decorridas doze horas realizou-se a filtragem a vácuo a fim de extrair a maior parte dos extratos. Após filtragem, os extratos foram resfriados, liofilizados e congelados para evitar decomposição.
Análise dos extratos aquosos: Os extratos brutos liofilizados foram diluídos em água até a concentração de 2,5; 5 e $10 \%$ e analisados quanto a osmolalidade, o pH e a condutividade elétrica (Tabela 1). Os valores de $\mathrm{pH}$ foram determinados em $\mathrm{pHmetro}$ digital modelo IA601, a condutividade em condutivímetro Analyser modelo 650 e a osmolalidade em osmomêtro de vapor de pressão modelo 5500 da marca Wescor.

Teste de Germinação: $O$ teste de germinação foi conduzido em estufa a temperatura

TABELA 1. Análises físico-químicas dos extratos.

\begin{tabular}{lcccc}
\hline \multicolumn{1}{c}{ Tipo de Extrato } & $\begin{array}{c}\text { Con centração } \\
(\%)\end{array}$ & $\mathbf{p H}$ & $\begin{array}{c}\text { Condu tividade elétrica } \\
(20 \mathrm{miliMO})\end{array}$ & $\begin{array}{c}\text { Osmolaridade } \\
\left(\mathrm{mM} \mathrm{kg}^{-1}\right)\end{array}$ \\
\hline \multirow{3}{*}{ Eclipta alba } & 2,5 & 7,69 & 0,85 & 56 \\
\cline { 2 - 5 } & 5 & 7,78 & 1,64 & 72 \\
\hline \multirow{3}{*}{ Gomphrena globosa } & 10 & 8,11 & 2,17 & 132 \\
\cline { 2 - 5 } & 2,5 & 6,09 & 1,98 & 57 \\
\hline \multirow{2}{*}{ Tabernaemontana catharinensis } & 5 & 6,21 & 3,38 & 77 \\
\cline { 2 - 5 } & 10 & 6,21 & 6,21 & 153 \\
\cline { 2 - 5 } & 2,5 & 7,00 & 0,95 & 56 \\
\hline \multirow{2}{*}{ Tithonia diversifolia } & 5 & 6,70 & 1,93 & 100 \\
\hline & 10 & 6,54 & 2,10 & 55 \\
\hline & 2,5 & 7,95 & 1,21 & 82 \\
\hline
\end{tabular}

de $25 \pm 2^{\circ} \mathrm{C}$, e sem controle de luminosidade e umidade. Os testes foram realizados em placas de Petri de $9 \mathrm{~cm}$ de diâmetro contendo duas folhas de papel de filtro autoclavadas a $120^{\circ} \mathrm{C}$ e embebidas em extrato bruto aquoso (EBA) nas concentrações de $2,5,5$ e $10 \%(p / V)$. Como testemunha foi utilizada a água destilada. A cada placa foram adicionadas 20 sementes das plantas testes espalhadas aleatoriamente sobre o papel por toda placa, a qual foi vedada com filme de PVC.

Antes da semeadura, as sementes comerciais de $L$. sativa e sementes de $B$. pilosa colhidas no campo foram tratadas com Nistatina (1\%, $\mathrm{p} / \mathrm{v}$ ) para evitar contaminações com fungos $e$ bactérias. Para plantas testes nenhum tratamento para quebra da dormência antes da semeadura foi realizado. O monitoramento da germinação para sementes de $L$. sativa foi realizado aos 3,7 e 10 dias e para B. pilosa aos 5, 10 e 15 dias.

$\mathrm{Na}$ avaliação da capacidade de germinação determinou-se o percentual de germinação e índice velocidade de germinação (IVG), e na avaliação do vigor das sementes foram coletados dados de peso seco das plântulas e sobrevivências destas. $O$ percentual de germinação foi calculado ao final do experimento, com 10 dias para L. sativa e 15 dias para B. pilosa. formula:

Para calculo do IVG, utilizou-se a seguinte

$$
I V G=\frac{100}{\mathrm{~N}} \Sigma \frac{\mathrm{ni}}{\mathrm{i}}
$$

onde $\mathrm{N}=$ número de sementes colocadas para germinar (ex.: 20); i = número de dias após a semeadura (ex.: 3, 7 e 10 para $L$. sativa); ni = número de sementes germinadas no dia i (ex.: $0,1,2, \ldots 20)$.

De acordo com metodologia Brasil (1992), as sementes de L. sativa foram consideradas germinadas quando apresentaram radículas superiores a $1 \mathrm{~mm}$ e as de $B$. pilosa quando as radículas foram superiores a $2 \mathrm{~mm}$. 
Para determinação da sobrevivência utilizouse a formula: $\%$ de plântulas sobreviventes $=100-$ (\% de plântulas mortas no final do experimento).

A massa seca das plântulas foi obtida após secagem em estufa a $50^{\circ} \mathrm{C}$ por $24 \mathrm{~h}$.

O delineamento experimental utilizado para as plantas teste foi o inteiramente casualizado (DIC) com 12 tratamentos dispostos em esquema fatorial $4 \times 3+T$, em três repetições, no qual constituíram os fatores principais os extratos das quatro espécies de plantas medicinais em três concentrações, com testemunha absoluta (Steel \& Torrie, 1960). Os dados obtidos foram submetidos a análise de variância pelo teste $F$ pelo programa ESTAT e as médias comparadas pelo teste Tukey aos níveis de significância de 1 e $5 \%$.

\section{RESULTADO}

Teste de germinação com $L$. sativa: De acordo com a Tabela 2, houve diferença significativa entre os efeitos dos tratamentos e a testemunha para germinação, IVG e sobrevivência das plantas e entre os tipos de extratos, entre as concentrações e na interação do tipo de extrato com as concentrações para as quatro variantes analisadas para planta teste L. sativa.

Com relação à germinação das sementes de $L$. sativa (Tabela 3 ), os extratos promoveram diferentes respostas. Extrato de E. alba em todas as concentrações e de T. diversifolia nas concentrações de 2,5 e $5 \%$ apresentaram maiores valores para germinação semelhante a testemunha. Extratos de G. globosa e T. catharinensis foram os que mais inibiram a germinação nas concentrações de 5 e $10 \%$. Não foi observada diferença significativa entre as germinações das sementes para as três concentrações utilizadas quando analisados os extratos de E. alba e G. globosa separadamente. Em contrapartida, os extratos de $T$. catharinensis e $T$. diversifolia apresentaram um maior efeito inibitório nas maiores concentrações.
Quando analisados os diferentes extratos para uma mesma concentração, observou-se que o extrato de G. globosa apresentou o maior poder inibitório independentemente da concentração utilizada. Os extratos de T. catharinensis a 5 e $10 \%$ e de $T$. diversifolia a $10 \%$ apresentaram os menores valores para germinação das sementes acarretando na diferença significativa das médias para Teste $F$ ao nível de $1 \%$ de probabilidade quando comparados a E. alba.

Com relação à análise para Índice de Velocidade de Germinação, nota-se que houve diferença significativa entre os efeitos dos tratamentos e da testemunha, entre os tipos de extratos, entre as concentrações e na interação do tipo de extrato com as concentrações. Segundo a Tabela 3, tanto entre diferentes extratos com mesma concentração quantos extratos similares com concentrações diferentes houve diferença significativa. Para extratos de $E$. alba e $T$. catharinensis, observa-se que as médias decresceram com aumento da concentração destes extratos. Para extratos de G. globosa e $T$. diversifolia, houve um decréscimo somente da concentração de 10\%. Quando comparado o IVG das sementes de L. sativa expostas aos diferentes extratos de plantas medicinais em uma mesma concentração, os maiores índices ocorreram nas sementes submetidas ao extrato de E. alba, independentemente da concentração.

Quando analisados diferentes extratos na concentração de $2,5 \%$ nota-se inferioridade das médias do extrato de $T$. diversifolia em relação aos demais. Para a concentração de 5\%, embora o extrato de $T$. diversifolia apresente baixos valores, as menores médias foram registradas com o extrato de $T$. catharinensis devido à alta mortalidade das plantas germinadas. Por fim, para concentração de $10 \%$, a análise demonstra menores índices para extratos de G. globosa e T. catharinensis devido a elevada mortalidade de plântulas e $T$. diversifolia devido a germinação tardia das sementes. Vale ressaltar que o extrato de G. globosa nas concentrações de 2,5 e $5 \%$ apresentou baixa

TABELA2. Resultado da análise de variância (valores F) para L. sativa.

\begin{tabular}{lcccc}
\hline Estatísticas & $\begin{array}{c}\text { Germinação } \\
(\%)^{1}\end{array}$ & IVG & $\begin{array}{c}\text { Massa seca das } \\
\text { plântulas (mg) }\end{array}$ & $\begin{array}{c}\text { Sobrevivência das plantas } \\
\text { germinadas (\%) }\end{array}$ \\
\hline Testemunha x Fatores & $26,14^{* *}$ & $129,11^{* *}$ & $0,01^{\text {NS }}$ & $18,38^{* *}$ \\
F extrato (E) & $82,92^{* *}$ & $71,91^{* *}$ & $198,82^{* *}$ & $79,82^{* *}$ \\
F concentração (C) & $35,07^{* *}$ & $310,50^{* *}$ & $18,33^{* *}$ & $23,47^{* *}$ \\
F interação (E x C) & $8,93^{* *}$ & $25,67^{* *}$ & $31,15^{* *}$ & $6,65^{* *}$ \\
\hline CV (\%) & 23,78 & 13,06 & 17,83 & 25,17 \\
\hline
\end{tabular}

*, ** Significativo ao nível de 5 e $1 \%$ de probabilidade, respectivamente, pelo teste F. NS Não significativo ao nível de $5 \%$ de probabilidade pelo teste F. ${ }^{1}$ Dados transformados para arc sen $(x / 100)^{1 / 2}$. 
TABELA 3. Efeito da interação entre as espécies de plantas e a concentração dos extratos sobre a germinação $(\%)^{2}$, Índice de Velocidade de Germinação, massa seca das plântulas e na sobrevivência (\%) de L. sativa.

\begin{tabular}{|c|c|c|c|c|c|c|c|c|c|c|}
\hline \multirow[b]{2}{*}{ Concentração } & \multicolumn{10}{|c|}{ Extratos } \\
\hline & \multicolumn{2}{|c|}{ E. alba } & \multicolumn{2}{|c|}{ G. globosa } & \multicolumn{2}{|c|}{ T. catharinensis } & \multicolumn{2}{|c|}{ T. diversifolia } & \multirow[t]{2}{*}{ Teste F } & \multirow[t]{2}{*}{ Média } \\
\hline \multicolumn{9}{|c|}{ Germinação $(\%)^{2}$} & & \\
\hline $2.5 \%$ & 70,80 & $A a^{1}$ & 15,00 & $\mathrm{~B} \mathrm{a}$ & 52,01 & A a & 68,66 & A a & $22,66^{* *}$ & 51,62 \\
\hline $5 \%$ & 76,84 & A a & 8,61 & $\mathrm{~B} \mathrm{a}$ & 11,07 & $\mathrm{~B}$ b & 64,70 & $\mathrm{~A}$ a & $42,92 * *$ & 40,30 \\
\hline $10 \%$ & 67,40 & A a & 0,00 & $\mathrm{~B} \mathrm{a}$ & 0,00 & $\mathrm{~B} \mathrm{~b}$ & 12,29 & $\mathrm{~B} b$ & 35,2 ** & 19,92 \\
\hline Teste F & $0,78^{N S}$ & & $1,93^{\mathrm{NS}}$ & & $25,51 *$ & & 33,65 * & & & \\
\hline Média & 71,68 & & 7,87 & & 21,03 & & 48,55 & & & \\
\hline \multicolumn{11}{|c|}{ Índice de Velocidade de Germinação } \\
\hline $2.5 \%$ & 49,4 & $\mathrm{Aa}^{1}$ & 41,3 & $\mathrm{~B} \mathrm{a}$ & 42,8 & $\mathrm{AB}$ a & 22,9 & $\mathrm{Ca}$ & $34,17^{* *}$ & 39,09 \\
\hline $5 \%$ & 40,1 & $A b$ & 41,3 & $\mathrm{~A} a$ & 7,3 & $\mathrm{Cb}$ & 20,2 & $\mathrm{~B}$ a & $71,87^{* *}$ & 27,23 \\
\hline $10 \%$ & 17,3 & Ac & 0,5 & $\mathrm{~B} b$ & 0,5 & $\mathrm{~B} \mathrm{C}$ & 3,5 & $\mathrm{~B} b$ & $17,22^{\star \star}$ & 5,45 \\
\hline Teste F & 72,54 ** & & 147,84 & & 137,78 & & 29,36 * & & & \\
\hline Média & 35,59 & & 27,67 & & 16,89 & & 15,56 & & & \\
\hline \multicolumn{11}{|c|}{ Massa seca das plântulas (mg) } \\
\hline $2.5 \%$ & 0,65 & $\mathrm{Aa}^{1}$ & 0,00 & $\mathrm{~B} \mathrm{a}$ & 0,75 & A a & 0,62 & A a & $67,87^{* *}$ & 0,50 \\
\hline $5 \%$ & 0,76 & A a & 0,00 & $\mathrm{Ba}$ & 0,00 & $\mathrm{~B} \mathrm{~b}$ & 0,65 & $\mathrm{~A}$ a & 98,64 ** & 0,35 \\
\hline $10 \%$ & 0,72 & A a & 0,00 & $\mathrm{Ba}$ & 0,00 & $\mathrm{~B} \mathrm{~b}$ & 0,67 & $\mathrm{~A}$ a & 94,61 ** & 0,35 \\
\hline Teste F & $1,89^{N S}$ & & $0,00^{N S}$ & & 109,42 & & $0,47^{\mathrm{NS}}$ & & & \\
\hline Média & 0,7073 & & 0,00 & & 0,2495 & & 0,6492 & & & \\
\hline \multicolumn{11}{|c|}{ Sobrevivência $(\%)^{2}$ das plântulas } \\
\hline $2.5 \%$ & 90 & $A a^{1}$ & 15,84 & $\mathrm{Ca}$ & 61,44 & $\mathrm{~B} \mathrm{a}$ & 82,40 & $A B a$ & $22,13^{* *}$ & 62,42 \\
\hline $5 \%$ & 90 & $\mathrm{Aa}$ & 8,84 & $\mathrm{Ba}$ & 15,87 & $\mathrm{~B} \mathrm{~b}$ & 78,32 & $\mathrm{~A} a$ & $34,87^{* *}$ & 48,26 \\
\hline $10 \%$ & 90 & $\mathrm{Aa}$ & 0,00 & $\mathrm{~B} \mathrm{a}$ & 0,00 & $\mathrm{~B} \mathrm{~b}$ & 23,08 & $\mathrm{~B} \mathrm{~b}$ & $36,12^{* *}$ & 28,27 \\
\hline Teste F & $0,00^{N S}$ & & $1,26^{\mathrm{NS}}$ & & 20,27 * & & 21,88 * & & & \\
\hline Média & 90 & & 8,23 & & 25,77 & & 61,27 & & & \\
\hline
\end{tabular}

${ }^{1}$ Médias seguidas por mesma letra não diferem entre si ao nível de $5 \%$ de probabilidade pelo teste de Tukey, sendo que letras maiúsculas comparam os efeitos das diferentes extratos dentro de uma mesma concentração e letras minúsculas comparam os efeitos dos diferentes concentrações dentro de um mesmo extrato. *, ${ }^{* *}$ Significativo ao nível de 5 e $1 \%$ de probabilidade, respectivamente, pelo teste F. NS Não significativo ao nível de $5 \%$ de probabilidade pelo teste F. ${ }^{2}$ Dados transformados para arc sen $(x / 100)^{1 / 2}$.

germinação, porém elevado IVG, o que demonstra inibição a partir da primeira semana após semeadura. Quanto à massa seca das plântulas, verificouse que não houve diferença significativa entre os efeitos dos tratamentos e testemunha, mas houve diferença significativa entre os tipos de extratos, entre as concentrações e na interação do tipo de extrato com as concentrações.

$\mathrm{Na}$ análise do efeito sobre cada extrato em diferentes concentrações, apenas $T$. catharinensis apresentou diferença significativa entre as três concentrações utilizadas. Neste extrato, observouse efeito inibidor sobre sementes e plântulas nas concentrações de 5 e $10 \%$. Além disso, notou-se alta mortalidade das plântulas e elevada necrose das raízes e hipocótilo no extrato de G. globosa a 2,5 e
$5 \%$ e o de $T$. catharinensis nas concentrações de $5 \%$. Extratos de G. globosa nas três concentrações e de $T$. catharinensis nas concentrações de 5 e $10 \%$ causaram a morte ou necrose das plântulas germinadas e, por isso, estas não apresentaram valores de biomassa no final do experimento.

Considerando todos os extratos e concentrações testadas, apenas $T$. catharinensis e T. diversifolia apresentaram diferenças significativas quanto a porcentagem de sobrevivência. $O$ extrato de G. globosa apresentou menores médias de sobrevivência independentemente das concentrações utilizadas. Além deste extrato, T. catharinensis na concentração de $5 \%$, também apresentou baixa porcentagem de sobrevivência. Por fim, os extratos de $10 \%$ de G. globosa e T. catharinensis inibiram 
totalmente a sobrevivência das plântulas, enquanto E. alba não interferiu nessa característica.

Teste de germinação para B. pilosa: Com relação aos resultados dos tratamentos que receberam diferentes concentrações dentro de um mesmo extrato, as quatro espécies apresentaram maior efeito inibitório nas maiores concentrações, sendo observada uma inibição total nos extratos de G. globosa e T. catharinensis para concentração de $10 \%$, semelhante ao ocorrido com os experimentos de L. sativa (Tabela 4). Além destes extratos, os demais apresentaram significativa redução da germinação com aumento da concentração, sendo efeito inibidor mais evidente na concentração de $10 \%$. Quando analisados diferentes extratos com mesma concentração, apenas os extratos a $5 \%$ apresentaram diferença significativa, sendo observada o maior efeito inibidor no extrato de G. globosa.

Conforme análise de variância, houve diferença significativa entre o efeito dos tratamentos e a testemunha, entre as concentrações e na interação do tipo de extrato com as concentrações para IVG. A concentração de $10 \%$ em todos os extratos avaliados apresentou menor índice de IVG. Para extratos de $G$. globosa e $T$. diversifolia houve ainda redução do IVG na concentração de $5 \%$, devido à alta mortalidade das plântulas e germinação tardia. Na concentração de 5\%, notou-se que os menores índices de IVG ocorreram nos extratos de G. globosa devido ao efeito inibidor deste extrato sobre germinação e crescimento das plântulas e os maiores índices foram observados nos extratos de $E$. alba com valores próximos ao da testemunha. Para massa seca das plântulas germinadas não houve diferença significativa entre os tratamentos e a testemunha, mas houve diferença significativa entre os tipos de extratos, entre as concentrações e na interação do tipo de extrato com as concentrações. Quando analisados diferentes extratos na mesma concentração, houve diferença significativa apenas para G. globosa e T. diversifolia na concentração de $5 \%$. Concentrações de $2,5 \%$ de

TABELA 4. Efeito da interação entre as espécies de plantas e a concentração dos extratos sobre a germinação $(\%)^{2}$, Índice de Velocidade de Germinação e massa seca das plântulas de B. pilosa.

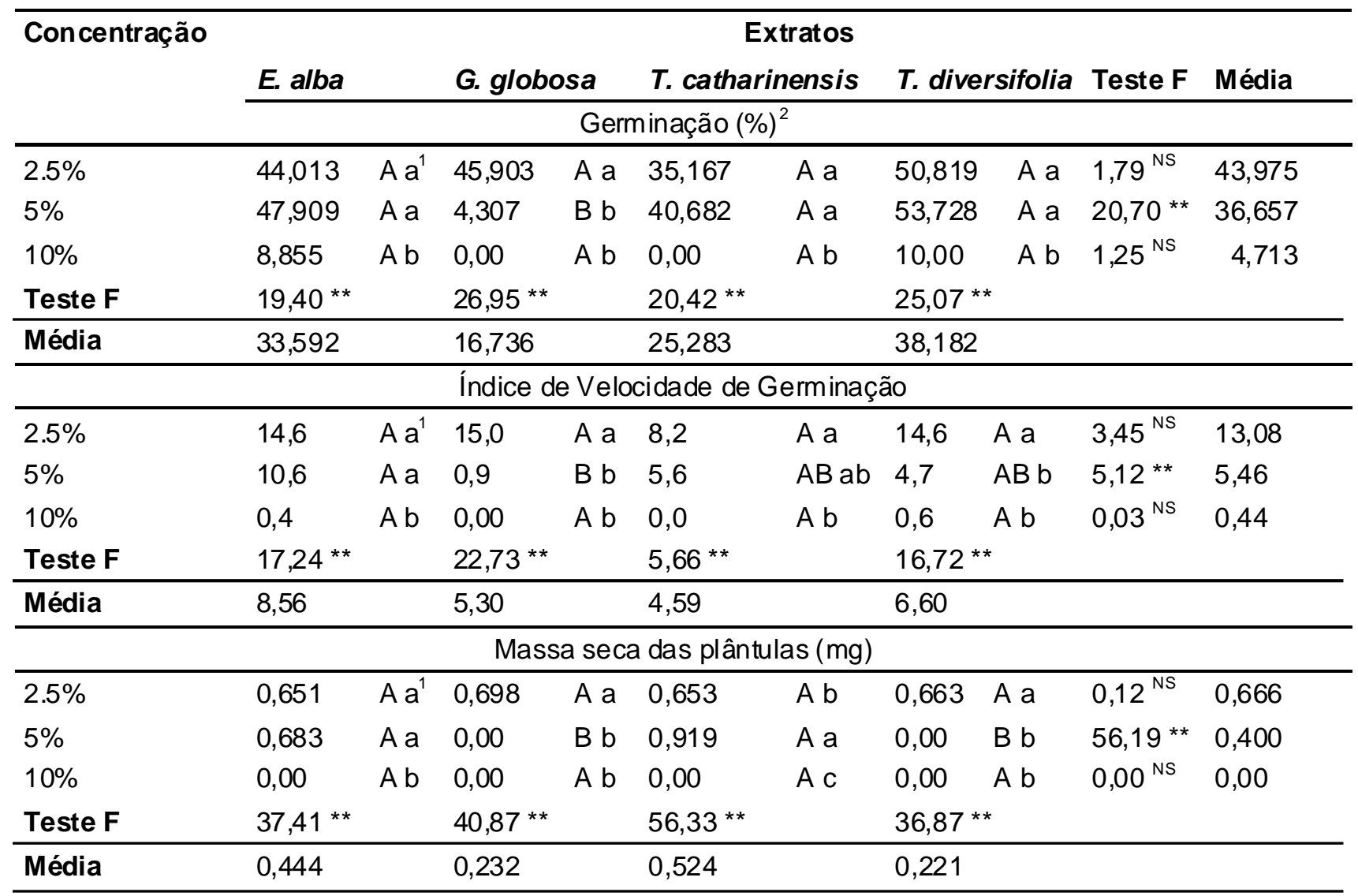

${ }^{1}$ Médias seguidas por mesma letra não diferem entre si ao nível de 5\% de probabilidade pelo teste de Tukey, sendo que letras maiúsculas comparam os efeitos das diferentes extratos dentro de uma mesma concentração e letras minúsculas comparam os efeitos dos diferentes concentrações dentro de um mesmo extrato. * ${ }^{* *}$ Significativo ao nível de 5 e $1 \%$ de probabilidade, respectivamente, pelo teste F. NS Não significativo ao nível de $5 \%$ de probabilidade pelo teste F. ${ }^{2}$ Dados transformados para arc sen $(\mathrm{x} / 100)^{1 / 2}$. 
todos os extratos das espécies testadas promoveram maior massa seca, enquanto que a concentração de $10 \%$ devido a morte ou necrose das plântulas, não apresentou biomassa.

De acordo com análise de variância para sobrevivência das plântulas, não houve diferença significativa entre os tipos de extratos e nem houve na interação do tipo de extrato com as concentrações, mas houve entre o efeito dos tratamentos e as diferentes concentrações (Tabela 5).

Analisando os fatores separadamente (Tabela
5), pode-se concluir que as concentrações de 5 e $10 \%$ foram as que apresentaram as maiores porcentagens de sobrevivência das plântulas independentemente do tipo de extrato. É importante ressaltar que as plântulas de $B$. pilosa apresentaram elevada germinação quando embebidas nos extratos a $2,5 \%$ das espécies analisadas; porém, a sobrevivência delas foi menor quando comparadas com aquelas crescidas em extratos a $10 \%$. Este resultado mostra que extratos em concentrações mais elevadas podem ser utilizados para selecionar vigor das plantas.

TABELA 5. Efeito das espécies de plantas e da concentração dos extratos a sobrevivência das plântulas² de $B$. pilosa.

\begin{tabular}{|c|c|c|c|c|c|}
\hline \multirow{3}{*}{$\begin{array}{l}\text { Concentração } \\
2.5 \%\end{array}$} & \multirow{2}{*}{\multicolumn{2}{|c|}{$\begin{array}{c}\text { So brevivên cia } \\
\text { (\%) }\end{array}$}} & \multirow{3}{*}{$\begin{array}{l}\text { Extratos } \\
\text { E. alba } \\
\text { G. globosa }\end{array}$} & \multicolumn{2}{|c|}{ Sobrevivência (\%) } \\
\hline & & & & \multirow{2}{*}{$\begin{array}{l}79,04 \\
76,08\end{array}$} & \multirow{2}{*}{$\begin{array}{l}A B \\
A B\end{array}$} \\
\hline & 65,81 & $\mathrm{~B}^{1}$ & & & \\
\hline $5 \%$ & 82,32 & $A$ & $\begin{array}{l}T . \\
\text { catharinensis }\end{array}$ & 72,37 & $\mathrm{~B}$ \\
\hline $10 \%$ & 90,00 & $A$ & T. diversifolia & 90,00 & A \\
\hline Teste F & $10,06^{* \star}$ & & Teste F & $2,84^{\mathrm{NS}}$ & \\
\hline
\end{tabular}

${ }^{1}$ Médias seguidas por mesma letra, na mesma coluna, não diferem entre si ao nível de $5 \%$ de probabilidade pelo teste de Tukey. ${ }^{2}$ Dados transformados para arc sen $(x / 100)^{1 / 2}$.

\section{DISCUSSÃO}

A germinação é menos sensível aos aleloquímicos que o crescimento da plântula (Ferreira \& Áquila, 2000). Entretanto com relação à quantificação experimental é muito mais simples, trabalhar com semente do que com planta adulta. Substâncias alelopáticas podem inibir ou não a germinação, além de induzir o aparecimento de plântulas anormais, sendo a radícula um dos sintomas mais comuns. Assim, a avaliação da normalidade das plântulas é instrumento importante na identificação de substâncias alelopáticas. Além disso, os autores descrevem alguns problemas usuais do teste de germinação, tais como: a necessidade do controle da temperatura, pois com a evaporação eleva-se a concentração dos extratos falseando os resultados, a utilização de duas ou três folhas de papel de filtro ou absorvente no fundo da placa e o uso de películas plásticas para vedar as tampas evitando dessecamento das placas e o uso de sementes de espécies cultivadas, de boa qualidade (Ferreira \& Áquila, 2000).

No presente trabalho, os extratos apresentaram efeito aleopático na germinação das sementes testadas. Dentre os diferentes resultados, notou-se que para ambas as plantas teste houve inibição total da germinação nos extratos de $G$. globosa e T. catharinensis na concentração de $10 \%$, semelhante ao descrito por Aqüila \& Azambuja (1996) que utilizaram extratos aquosos em diversas concentrações de Crysophylum gonocarpum em sementes de $L$. sativa e relataram que não houve inibição do crescimento na concentração de $2 \%$ mas houve inibição da germinação nas concentrações de 5 e $10 \%$. Ou seja, com aumento da concentração do extrato nota-se aumento do efeito inibitório na germinação das sementes.

Ainda com relação à germinação, o efeito alelopático em geral não é sobre a germinabilidade (porcentagem final de germinação no tempo), mas sobre o Índice de Velocidade de Germinação (Labouriau, 1983; Rodrigues et al., 1999). Os extratos de G. globosa e T. catharinensis, quando em contato com as sementes das plantas testes, causaram baixo IVG devido à elevada mortalidade das plântulas. Em relação ao extrato a $10 \%$ de $T$. diversifolia, o baixo índice de germinação ocorreu devido a germinação tardia das sementes. Esses resultados corroboram com os obtidos por outros pesquisadores uma vez que demonstram efeito inibitório do extrato aquoso de folhas de $T$. diversifolia na germinação e crescimento, relatando também que esta atividade inibitória é dependente da espécie de planta teste utilizada (Tongma et al.,1998). Os aleloquímicos presentes no girassol retardaram a germinação das sementes de algumas espécies de plantas daninhas, sendo tal resposta dependente da concentração do extrato, e que elevadas concentrações são mais 
eficientes dependendo da planta teste utilizada (Ciarka et al., 2002).

Com relação ao massa seca e sobrevivência das plântulas, há aleloquímicos que afetam o crescimento das plântulas além de induzir o aparecimento de plântulas anormais, como por exemplo, plantas com partes necrosadas (Ferreira \& Áquila, 2000). Dentre os resultados apresentados neste trabalho, destaca-se que o extrato de $G$. globosa na concentração de $5 \%$ que apresentou efeito inibidor no crescimento das plântulas das plantas teste. Analisando somente os resultados para $L$. sativa, nota-se que o extrato de G. globosa a 2,5\% e o extrato de $T$. catharinensis a $5 \%$ apresentaram efeito inibitório do crescimento, pois, impediram o desenvolvimento das plântulas causando a morte a partir da primeira semana após iniciar o experimento. Para B. pilosa, o efeito sobre o crescimento das plântulas foi observado quando estas se desenvolveram em contato com os extratos de $T$. diversifolia nas concentrações de 5 e 10\%. Determinados extratos em baixa concentração podem suprimir o crescimento de determinadas espécies, mas não de outras, isso mostra que não há padrão de respostas quanto à concentração, necessitando sempre testes específicos envolvendo plantas teste e concentração do extrato (Premasthira \& Zungsontiporn, 1996).

Além disso, o efeito do tipo de extrato depende da sensibilidade da planta teste para com o aleloquímico, sendo que, em determinadas espécies uma substância alelopática pode ser inibidora da germinação ou do crescimento, e em outra esta mesma substância pode ser inócua ou estimulante (Almeida, 1988). Os extratos aquosos das espécies em estudo apresentam na constituição compostos fenólicos em decorrência do poder de extração da água por moléculas polares, tais como flavonóides ( $T$. diversifolia, E. alba e G. globosa) e alcalóides indólicos em T. catharinensis (Pomillio et al., 1994; Pereira et al., 1997; Pereira et al.,1998; Pratchayasakul et al., 2008; Lee et al., 2009). Um estudo com vários extratos de plantas medicinais da maioria das espécies testadas reduziram a germinação das sementes de $A$. retroflexus e $C$. murale, sendo que o grau de inibição variou para as diferentes plantas medicinais testadas e que algumas espécies não mostraram efeito prejudicial e até mesmo estimularam o crescimento das plantas teste (Qasem, 2002). A resposta da germinação de $B$. kaber depende da fonte do extrato, da concentração e da espécie utilizada e o efeito estimulante de extratos diluídos de $H$. annuus sobre germinação de $B$. kaber, acarretou aumento de produção superior a $150 \%$ (Leather, 1983).

O efeito alelopático dos extratos testados foi confirmado pela baixa sobrevivência das plantas testes, desenvolvidas sob a ação dos extratos de $G$ globosa, nas três concentrações do extrato de $T$. catharinensis (5 e $10 \%$ ) e do extrato de T. diversifolia (10\%). Em relação a eficácia das plantas teste constatou-se que $L$. sativa devido o poder de germinação foi mais eficiente do que $B$. pilosa para demonstrar o efeito alelopático dos extratos estudados.

\section{CONCLUSÃO}

O extrato de G. globosa apresentou efeito inibidor na germinação de sementes na concentração de $10 \%$ e no crescimento das plântulas em concentrações de 2,5 e $5 \%$ para as plantas teste. 0 extrato de T. catharinensis também apresentou efeito inibitório na porcentagem de germinação das sementes nas concentrações de 5 e $10 \%$ para $L$. sativa e $10 \%$ para $B$. pilosa. Para o extrato de $T$. diversifolia, verificou-se que nas três concentrações analisadas ocorreu germinação tardia das sementes, reduzindo o valor do IVG. Verificou-se que o extrato E. alba estimulou a germinação e crescimento das plântulas. A germinação das sementes mostrou-se mais sensíveis aos aleloquímicos presentes nos extratos do que o crescimento das plantas. A planta teste de $L$. sativa, devido ao poder de germinação, foi mais eficiente do que $B$. pilosa para demonstrar o efeito alelopático dos extratos estudados.

\section{REFERÊNCIA}

ACHENBACH, H.; WAIBEL, R.; ZWANZGER, M. Indole alkaloids from Tabernaemontana glandulosa. Phytochemistry, v.37, n.6, p.1737-43, 1994.

ALMEIDA, F.S. Alelopatia e as plantas. Londrina: IAPAR, 1988. 68p. (Circular, 53).

AQÜILA, M.E.A.; AZAMBUJA, F.J. Allelopathy in a natural Brazilian woodland. Evaluation of the Crysophilum gonocarpum (Aguai). In: WORLD CONGRESS ON ALLELOPATHY, 1., 1996, Cádiz. Abstract... Cádiz: International Allelopathy Society, 1996. p.57.

BAIS, H.P. et al. The role of root exudates in rhizosphere interactions with plants and other organisms. Annual Review of Plant Biology, v.57, p.233-66, 2006.

BANERJI, A. et al. Isolation of ecdysterone from Indian plants. Phytochemistry, v.10, n.9, p.2225-6, 1971.

BARUAH, N.C. et al. Sesquiterpene lactones of Tithonia diversifolia. Steriochemistry of the tagitinins and related compounds. Journal of Organic Chemistry, v.44, n.11, p.1831-5, 1979.

BRASIL. Ministério da Agricultura. Regras para análise de sementes. Brasília: Departamento Nacional de Produção Vegetal, Divisão de Sementes e Mudas, 1992. 365p.

CIARKA, D.; GAWRONSKA, H.; GAWRONSKI, S.W. Weed species reaction to sunflower allelopathics. In: WORLD CONGRESS ON ALLELOPATHY, 3., 2002, Ibaraki.

Rev. Bras. PI. Med., Botucatu, v.13, n.3, p.328-336, 2011. 
Abstract ... Cádiz: International Allelopathy Society, 2002. p.162.

DUKE, S.O. et al. Natural products as sources of herbicides: current status and future trends. Weed Research, v.10, p.99-111, 2000.

EINHELLIG, F.A. Interactions involving allelopathy in cropping systems. Agronomy Journal, v.8, n.6, p.886-93, 1996.

FERREIRA, A.G.; AQUILA, M.E.A. Alelopatia: uma área emergente da ecofisiologia. Revista Brasileira de Fisiologia Vegetal, v.12, p.175-204, 2000.

HEROUT, V. Chemotaxonomy of the family Compositae (Asteraceae). In. WAGNER, H.; HORMHANMER, L. (Eds.). Pharmacognosy and Phytochemistry. Berlin: SpringerVerlag, 1971. p.94.

INDERJIT; DUKE, S.O. Ecophysiological aspects of allelopathy. Planta, v.217, n.4, p.529-39, 2003.

KUGLER, F.; STINTZING, F.C.; CARLE, R. Characterisation of betalain patterns of differently coloured inflorescences from Gomphrena globosa L. and Bougainvillea sp. by HPLC-DAD-ESI-MSn. Analytical and Bioanalytical Chemistry, v.387, n.2, p.637-48, 2007.

KUMAR, G.; GAUTAM, N. Allelotoxicity of Parthenium leaf extracts on cytomorphological behaviour of sunflower (Helianthus annuus). Journal of Environmental Biology, v.29, n.2, p.243-7, 2008.

KUO, Y.H.; CHEN, C.H. Sesquiterpenes from the leaves of Tithonia diversifolia. Journal of Natural Products, v.61, n.6, p.827-8, 1998.

KURODA, M. et al. Oleanane and taraxerane glycosides from the roots of Gomphrena macrocephala. Journal of Natural Products, v.69, n.11, p.1606-10, 2006.

LABOURIAU, L.G. A germinação das sementes. Washington: OEA, 1983. 174p.

LEATHER, G.R. Sunflower (Hellianthus annuus) are allelopathic to weed. Weed Science, v.31, p.37-42, 1983. LEE, M.K. et al. Stimulatory constituents of Eclipta prostrata on mouse osteoblast differentiation. Phytotheraphy Research, v.23, n.1, p.129-31, 2009.

LEEUWEMBERG, A.J.M. A revision of Tabernaemontana: the new world species and Stemmadenia. Kew: The Royal Botanic Gardens, 1994. v.2, 442p.

MACÍAS, F.A. et al. Allelopathy - a natural alternative for weed control. Pest Management Science, v.63, n.4, p.32748, 2007.

NIELSEN, H.B. et al. Indole alkaloids and terpenoids from Tabernaemontana markgrafiana. Phytochemistry, v.37, n.6, p.1729-35, 1994

PATTERSON, G.W.; XU, S.; SALT, T.A. Sterols of caryophyllales with emphasis on amaranthaceae. Phytochemistry, v.30, n.2, p.523-6, 1970.

PEREIRA, P.S. et al. Sesquiterpenes lactones from Brazilian Tithonia diversifolia (Hemsl) A.Gray. Phytochemistry, v.45, n.7, p.1445-8, 1997.

PEREIRA, A.M.S. et al. Soil $\mathrm{pH}$ and production of biomass and wedelolactone in field grown Eclipta alba. Jornal of Herbs, Spices and Medicinal Plants, v. 6, p. 43-7, 1998. PÉREZ, A.L.C.; LARA, M.O.; DE VIVAR, A.R. Sesquiterpenoids and diterpenoids from Tithonia longiradiata. Phytochemistry, v.31, n.12, p.4227-31, 1992. POMILIO, A.B. et al. Antitumor and cytotoxic screen of 5,6,7trisubstituted flavones from Gomphrena martiana. Journal of Ethnopharmacology, v.44, n.1, p.25-33, 1994.

PRATCHAYASAKUL, W. et al. Ethnobotany \& ethnopharmacology of Tabernaemontana divaricata. Indian Journal of Medical Research, v.127, n.4, p.317-35, 2008. PREMASTHIRA, C.; ZUNGSONTIPORN, S. Bioefficacy of sesame. In: WORLD CONGRESS ON ALLELOPATHY, 1., 1996, Cadiz. Abstract ... Cádiz: International Allelopathy Society, 1996. p.264.

QASEM, J.R. Allelopathic effects of selected medicinal plants on Amaranthus retroflexus and Chenopodium murale. Allelopathy Journal, v.10, n.2, p.105-22, 2002.

RICE, E.L. Allelopathy. 2 ed. New York: Academic Press, 1984. 422p.

RODRIGUES, B.N.; PASSINI, T.; FERREIRA, A.G. Research on allelopathy in Brazil. In: NARWAL, S.S. (Ed.). Allelopathy update. Enfield: Science Pub, 1999. v.1, p.307-23.

SCHUSTER, A. et al. Sesquiterpene lactones from two Tithonia species. Phytochemistry, v.31, n.9, p.3139-41, 1992.

STEEL, R.G.; TORRIE, J.H. Principles and procedures of statistics with special reference to the biological sciences. New York: Mc Graw - Hill, 1960. 481p.

TONGMA, S.; KOBAYASHI, K.; USUI, K. Allelopathic activity of Mexican sunflower (Tithonia diversifolia) in soil. Weed Science, v.46, n.4, p.432-7, 1998.

VAN BEEK, T.A. et al. Tabernaemontana L. (Apocynaceae): a review of its taxonomy, phytochemistry, ethnobotany and pharmacology. Journal of Ethnopharmacology, v.10, n.1, p.1-156, 1984.

WAGNER, $H$. et al. Coumestans as the main active principles of the liver drugs Eclipta alba e Wedelia calendulaeae. Planta Medica, v.5, p.370-4, 1986. 